This item was submitted to Loughborough's Research Repository by the author.

Items in Figshare are protected by copyright, with all rights reserved, unless otherwise indicated.

\title{
Outdoor testing of anti-soiling hydrophobic coatings: Observations of cementation
}

PLEASE CITE THE PUBLISHED VERSION

https://doi.org/10.1109/pvsc45281.2020.9300590

PUBLISHER

IEEE

VERSION

AM (Accepted Manuscript)

\section{PUBLISHER STATEMENT}

Personal use of this material is permitted. Permission from IEEE must be obtained for all other uses, in any current or future media, including reprinting/republishing this material for advertising or promotional purposes, creating new collective works, for resale or redistribution to servers or lists, or reuse of any copyrighted component of this work in other works.

\section{LICENCE}

All Rights Reserved

\section{REPOSITORY RECORD}

Ulicna, Sona, Farwah Bukhari, Fabiana Lisco, Gizelle C Oehler, Kurt L Barth, and Michael Walls. 2021. "Outdoor Testing of Anti-soiling Hydrophobic Coatings: Observations of Cementation". Loughborough University. https://hdl.handle.net/2134/13602998.v1. 


\section{Outdoor Testing of Anti-Soiling Hydrophobic Coatings: Observations of Cementation}

\author{
Soňa Uličná \\ CREST, \\ Loughborough University \\ Leicestershire, UK \\ S.Ulicna@lboro.ac.uk
}

\author{
Farwah Bukhari \\ CREST \\ Loughborough University \\ Leicestershire, UK \\ S.U.F.Bukhari@lboro.ac.uk \\ Kurt L. Barth \\ $N G P V$ \\ Colorado State University \\ Fort Collins, USA \\ kurt.barth@colostate.edu
}

\author{
Fabiana Lisco \\ CREST \\ Loughborough University \\ Leicestershire, UK \\ F.Lisco@lboro.ac.uk \\ John M. Walls \\ CREST \\ Loughborough University \\ Leicestershire, UK \\ J.M.Walls@lboro.ac.uk
}

\author{
Gizelle C. Oehler \\ CREST \\ Loughborough University \\ Leicestershire, UK \\ gizelleoehler@gmail.com
}

\begin{abstract}
It is of an increasing interest for the solar research community to understand and master the effects of environmental conditions on photovoltaic (PV) module performance and reliability. This study demonstrates that soiling is not only an issue for PV installed in dusty and dry regions of The Middle East and North Africa. Soiling is a global problem and the type of soiling and its extent is dependent on the geographical location. Cementation, a process by which particles strongly adhere to the surface, has been observed on all surfaces exposed outdoors in a coastal location of Denmark and experiments are ongoing in two different geographical locations and climates. Applying hydrophobic coatings to PV module cover glass is a potential solution to minimize soiling. Although the use of a hydrophobic coating was initially effective, its gradual degradation was linked to the build-up of surface cementation. Degradation of the hydrophobic surface chemistry increases surface energy and leads to the formation of hard to remove cementation. This results in the retention of droplets and particles causing a reduction in the optical transmission into the module.
\end{abstract}

Keywords-hydrophobic, anti-soiling, coatings, outdoor exposure, cementation, durability, optical transmission

\section{INTRODUCTION}

Soiling of solar module cover glass is an important but often neglected operational issue facing solar asset managers. Accumulation of dirt, dust, pollen, snow, ice and other particles on the solar module cover glass can significantly reduce the light transmitted to the active absorber and hence reduce the power output from the module [1,2]. Among many active and passive soiling mitigation strategies, the application of a thin layer of an anti-soiling coating on the module cover glass is a simple and promising solution to minimize soiling and to maintain the power output along with the return on investment [2,3]. In principle, hydrophobic coatings are low surface energy coatings that may be well suited for this purpose. Their high water contact angle (WCA) (ideally $>120^{\circ}$ ) and low roll off angle (RoA) (ideally $<10^{\circ}$ ) reduces adhesion of incident particles. Also rain or cleaning water droplets remain roughly spherical and roll off the tilted module carrying away the soiling particles [4]. Several approaches to coating chemistry and application methods have been taken, but current formulations are failing to produce a coating able to withstand the challenge of outdoor conditions
[5,6]. PV modules are exposed outdoors 24/7, all year round, and subjected to regular cleaning cycles. The coating must be chemically stable and abrasion resistant.

We have assessed a number of candidate hydrophobic coatings used in other applications, such as on displays and ophthalmic lenses. These coatings are being tested in the laboratory in parallel with outdoor testing. This strategy informs the development of a more durable second-generation coating designed for solar modules. The laboratory tests follow IEC protocols and include UV exposure, damp heat exposure, temperature cycling, abrasion and sand impact tests. Such accelerated lifetime tests are useful to compare the durability of coatings and to uncover the mechanisms involved in degradation. However, outdoor exposure combines all these environmental stresses together and coating degradation occurs much faster than would be anticipated from the laboratory tests [7]. Moreover, particles and other soiling are present in the outdoor environment that are location dependent (salts, pollens, sand etc.). These can be anchored to the coating/glass surface in a process of cementation and are difficult to remove even by mechanical cleaning. Cementation lowers the transmittance through the cover glass. It also impedes the 'self-cleaning' properties of the coating.

In this work, we have exposed candidate hydrophobic coatings outdoors in a coastal location of Denmark for up to 24 weeks. The types of cementations formed on the coatings have been monitored and transmittance through the coated coupons was measured and compared to the uncoated and coated cleaned coupons. Similar experiments of outdoor exposure are being conducted in two different locations: rainy inland England and dry and cold mid-continent Colorado.

\section{EXPERIMENTAL}

\section{A. Hydrophobic coatings}

Hydrophobic coatings were applied onto glass coupons. The candidate coatings had different chemistry but generally, the presence of fluorinated surfaces or/and nanoparticles are responsible for their hydrophobicity. For each type of coating, 12 uncoated glass coupons (as a reference) and 12 coated 
coupons were prepared for each location to be exposed outdoors. One coated and one uncoated coupon of each type was removed from the rack each month for analysis. Figure 1 shows how the coated and uncoated coupons were mounted and exposed outdoors.

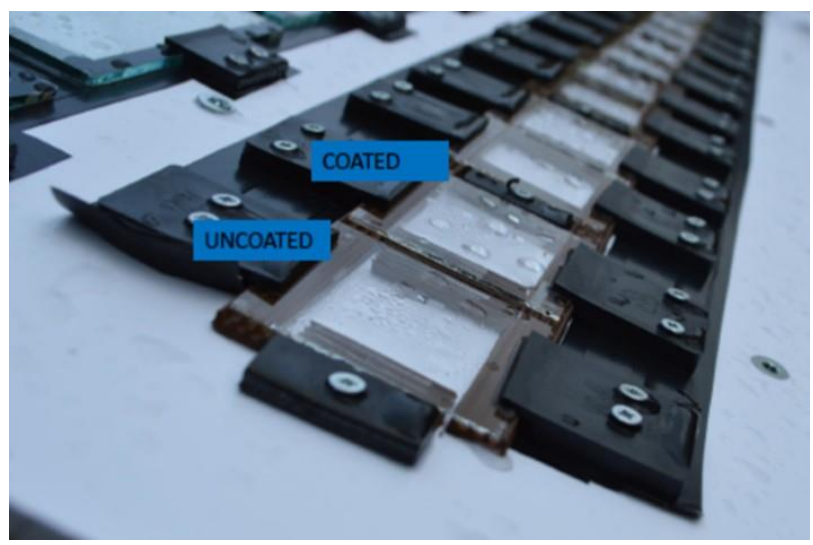

Fig. 1. Outdoor exposure of the glass coupons (coated and uncoated).

\section{B. Outdoor exposure}

The 6 months outdoor exposure of the coatings took place from mid-February till mid-August. The coupons were exposed in the coastal city of Esbjerg in Denmark $\left(55.5^{\circ} \mathrm{N}\right.$ latitude, $8.5^{\circ} \mathrm{E}$ longitude) on a ground mounted rack located $2 \mathrm{~km}$ away from the sea, $11 \mathrm{~km}$ from a weather station and in direct proximity of bushes and plants. Esbjerg is an oceanic location with mild temperatures throughout the year, high relative humidity and frequent light rainfall.

\section{Characterization}

Surface and cross-sectional images of the coated and uncoated coupons were obtained using a scanning electron microscope (JEOL 7800F FEGSEM) equipped with an Oxford Instruments EDX detector for elemental analysis. The hydrophobic properties of the coatings during exposure were monitored by measuring water contact angle (WCA) and roll off angle (RoA). The transmittance of the coated and uncoated coupons was measured using Varian Cary UV-Vis spectrophotometer in the wavelength range of 300-800 nm.

\section{RESULTS AND DISCUSSION}

Preliminary findings of the outdoor exposure of candidate coatings are presented in this extended abstract. Cementation was observed on two types of hydrophobic coating (one containing nanoparticles and one with a fluorinated surface without nanoparticles). Uncoated glass was also monitored as a control reference. Cementation takes place when impurities become trapped and anchored on the surface during the droplet condensation and evaporation cycles [7]. Cementation typically occurs in locations with high relative humidity, diurnal temperature variations which lead to the formation of dew and places where rainfall is frequent. Cemented particles are difficult to remove, and their presence reduces the optical transmittance, increases the RoA, but can also cause damage to the cover glass surface by abrasion during cleaning. Figure 2 shows a selection of different types of cementations observed on the coated and uncoated surfaces.

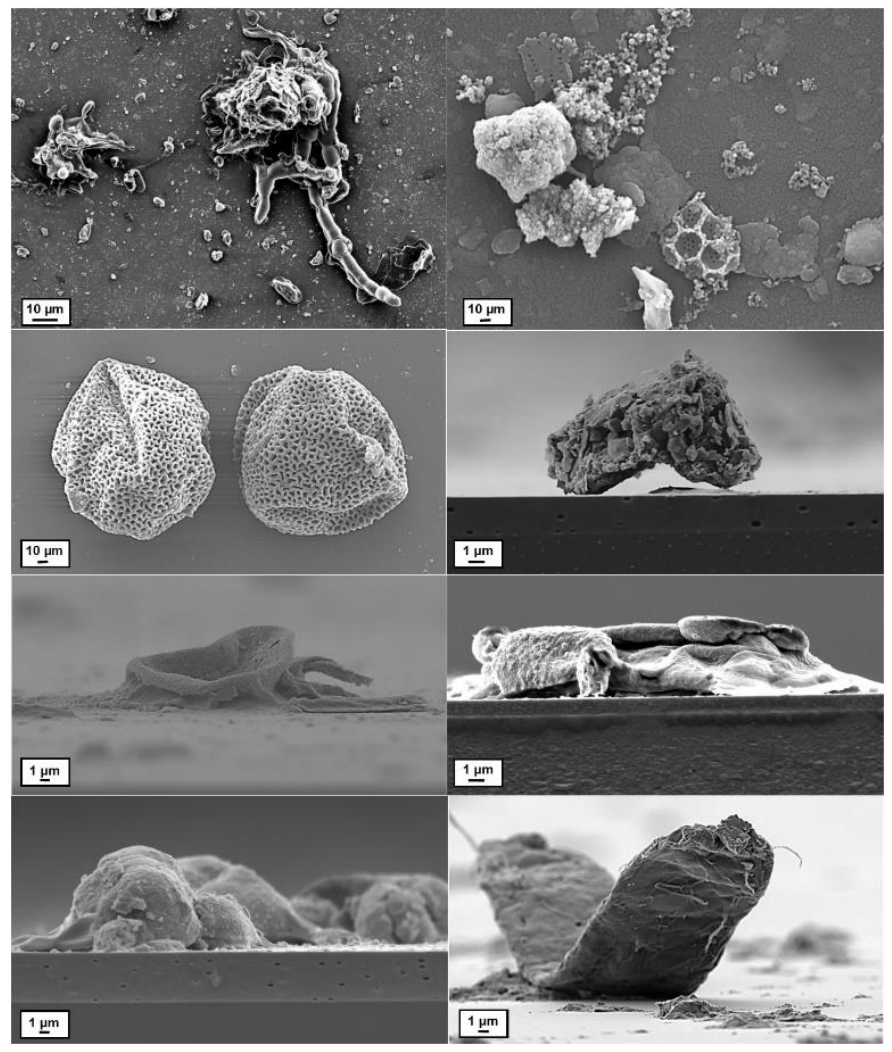

Fig. 2. Example of cemented particles observed on the surface of coated and uncoated coupons at various times during outdoor exposure in Denmark.

These results show that there is no apparent trend in the type, shape and size of the cemented particles found on coated and uncoated surfaces. This means that similar particles in similar concentrations were observed on all three coated and uncoated surfaces. The cemented particles observed varied in shape. The size was typically between $10-40 \mu \mathrm{m}$. Chemical analysis of the particles showed that the most common elements found were $\mathrm{C}$, $\mathrm{Na}, \mathrm{Cl}, \mathrm{Fe}, \mathrm{Mg}, \mathrm{Ca}, \mathrm{Al}, \mathrm{K}$ suggesting that the cemented particles are of both, organic and inorganic composition. EDX elemental images obtained from a cemented particle on a coated surface are shown in Figure 3.

Although the exposure at different locations is at an early stage, it is anticipated that the elements present in the cemented particles will be significantly different depending on the climate of the location. For instance $\mathrm{Cl}$ found in the cemented particle in Figure 3 can be likely attributed to the salt carried by the wind in the coastal location in Denmark. The inland location of Colorado is not expected to show this type of cemented particle.

Coating degradation and associated cementation caused the WCA of the coated surfaces to progressively decrease over time. The RoA increased even after only a few weeks of exposure. The RoA quickly exceeded the tilt angle at which the coupons were held. Due to the high RoA, the coatings were inefficient in removing particles from the surface. The soiling decreased the transmittance of the coupon. Mechanically assisted cleaning of the coupons partially restored the transmittance, but both 
candidate coatings were vulnerable to damage by abrasion by the cleaning process. Figure 4 shows the transmittance of a coated coupon prior to and after being exposed outdoors for 3 and 6 months. The transmittance was partially restored when coupons were cleaned using water, IPA and a microfiber cloth.
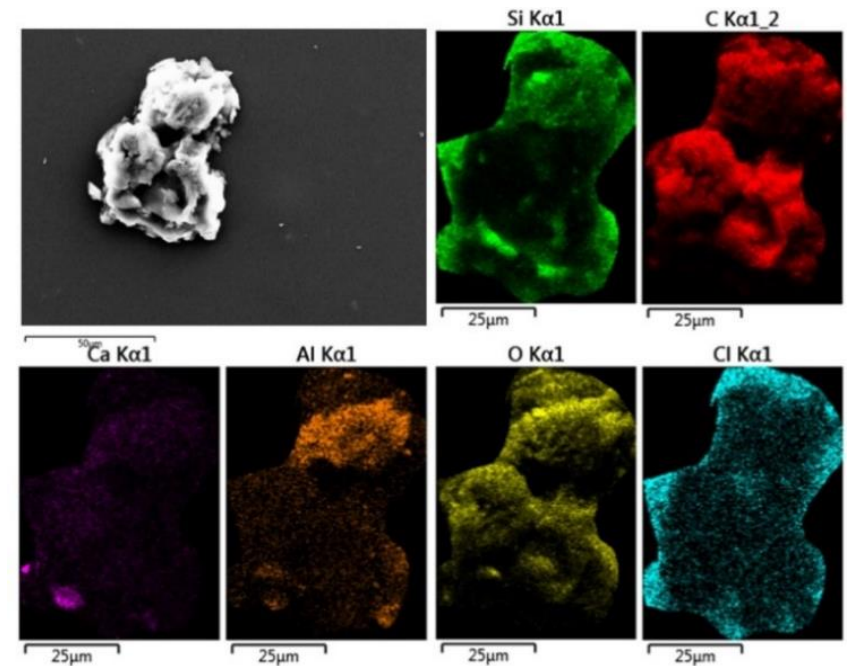

Al $K \alpha 1$
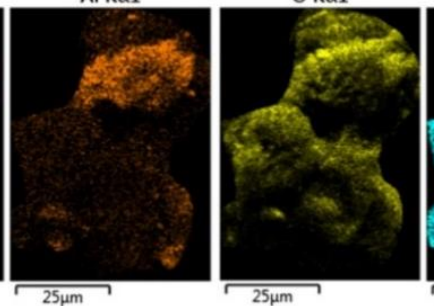

$\mathrm{CI} K \alpha 1$
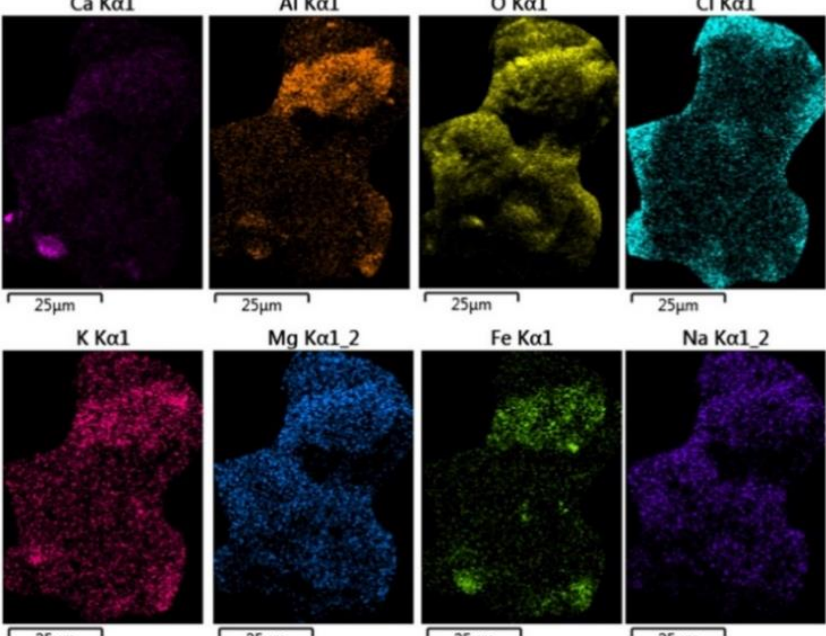

$\mathrm{Mg} \mathrm{Ka1 \_ 2}$

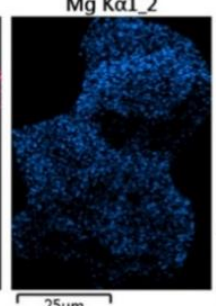

$\mathrm{Fe} \mathrm{K \alpha}$

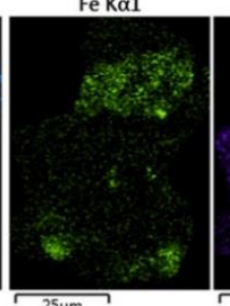

Na Ka1_2

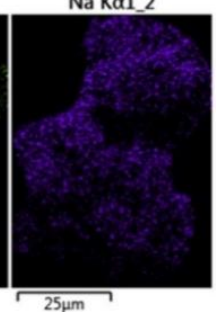

Fig. 3. SEM-EDX analysis of a cemented particle showing images of the detected elements. Oxygen and silicon signals are from the glass and the hydrophobic coating.

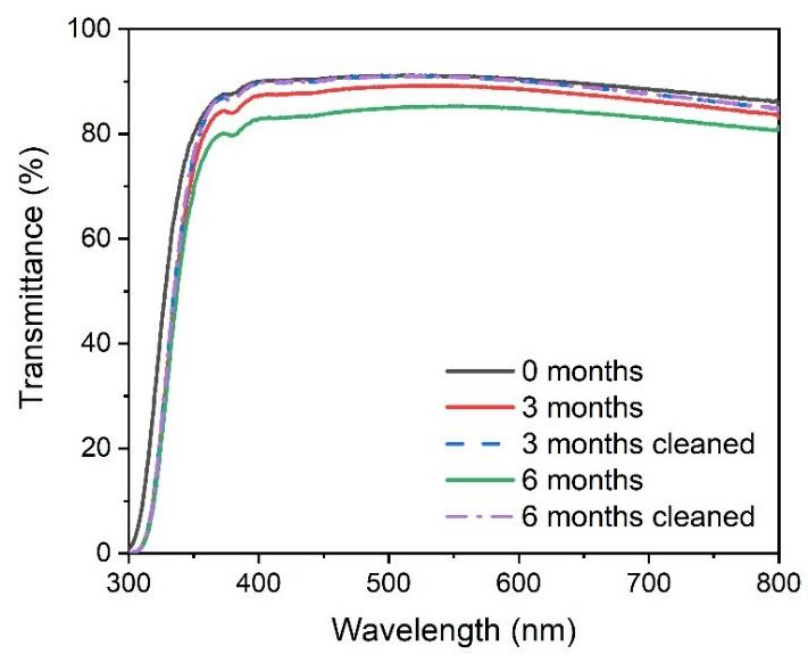

Fig. 4. Transmittance through the coated coupons after increasing times of outdoor exposure.

\section{CONCLUSIONS}

Uncoated and coated glass coupons with hydrophobic coatings have been exposed outdoors to study the effects of soiling. Particle cementation was observed on all coupons exposed outdoors. Particles such as dust, pollen or salt strongly adhere to the surface resulting in reduced transmittance, reduced WCA and increased RoA. No link was found between the type of surface (coated, uncoated) or the type of coating, and cementation (shapes, types and sizes). However, the cemented particles are expected to differ in type and composition for different geographical locations Experiments of outdoor exposure of hydrophobic coatings in more locations are ongoing to confirm this. Hydrophobic coatings have great potential to mitigate the effects of soiling for the solar application. However, the outdoor environment is very challenging and coating degradation occurs surprisingly quickly. Research is needed to improve coating durability. Laboratory and outdoor testing is revealing the vulnerabilities of currently available coatings and guiding the development of new anti-soiling formulations.

\section{REFERENCES}

[1] E. F. Cuddihy, "Theoretical considerations of soil retention," Sol. Energy Mater., vol. 3, pp. 21-33, 1980.

[2] T. Sarver, A. Al-Qaraghuli and L. L. Kazmerski, "A comprehensive review of the impact of dust on the use of solar energy: History, investigations, results, literature and mitigation approaches," Renew. Sustain. Energy Rev., vol. 22, pp. 698-733, 2013.

[3] Y.-B. Park, H. Im, M. Im and Y.-K. Choi, "Self-cleaning effect of highly water-repellent microshell structures for solar cell applications," J. Mater. Chem., vol. 21, pp. 633-636, 2011.

[4] S. S. Latthe, S. L. Dhere, C. Kappenstein, H. Imai, V. Ganesan, A. Venkateswara Rao, P. B. Wagh and S. C. Gupta, "Sliding behaviour of water drops on sol-gel derived hydrophobic silica films," Appl. Surf. Sci., vol. 256, pp. 3259-3264, 2010.

[5] S. Toth, M. Muller, D.C. Miller, H. Moutinho, B. To, L. Micheli, J. Linger, C. Engtrakul, A. Einhorn and L. Simpson, "Soiling and cleaning: Initial observations from 5-year photovoltaic glass coating durability study," Sol. Energy Mater. and Sol. Cells, vol. 185, pp. 375-384, 2018.

[6] B. Strauss, F. Lisco, F. Bukhari, J. M. Walls and K. L. Barth, "Novel hydrophobic coatings for soiling mitigation in the PV industry: durability and anti-soiling demonstrations," 2019 IEEE 46 ${ }^{\text {th }}$ Photovoltaic Specialist Conference, Chicago, Il, 2019.

[7] G. C. Oehler, F. Lisco, F. Bukhari, S. Uličná, B. Strauss, K. L. Barth and J. M. Walls, "Testing the durability of anti-soiling coatings for solar cover glass by outdoor exposure in Denmark," Energies, vol. 13, p. 299, 2020. 